\title{
Análise dos Artigos na Área da Deficiência Visual Publicados na ReVista Brasileira de EducaÇão Especial (1992-2017) ${ }^{1}$ \\ Analysis of Papers on Visual Impairment Published in the Brazilian JOURNAL OF SPECIAL EDUCATION (1992-2017)
}

\author{
Celi Corrêa NERES ${ }^{2}$ \\ Nesdete Mesquita CORRÊA ${ }^{3}$
}

\begin{abstract}
RESUMO: Este estudo objetivou analisar os artigos na área da deficiência visual publicados na Revista Brasileira de Educação Especial - RBEE, desde a sua criaçáo, em 1992, até 2017, visando evidenciar o registro dessa área nas publicaçóes veiculadas nesse periódico. $\mathrm{Na}$ coleta do material, foram identificadas 46 publicações, sendo três resenhas, um comentário e 42 artigos nos gêneros textuais ensaio, revisão de literatura e relato de pesquisa. Foram excluídos da análise o comentário e as resenhas. Para a leitura e a análise dos 42 artigos, foram adotados os seguintes eixos: distribuição anual dos artigos, autoria, temas apresentados, regióes e instituiçóes de origem, gêneros textuais e interfaces com outras áreas do conhecimento. Os resultados mostraram que a área da deficiência visual está presente na produção acadêmica, com maior evidência nas duas últimas décadas. Os temas dos artigos constituíram-se por diferentes áreas do conhecimento, com destaque para a interface com a área das Ciências da Saúde. Os indicadores de regiōes e de instituiçōes de origem dos artigos revelaram que, embora a RBEE divulgue estudos de origem internacional, em âmbito nacional, os artigos năo abrangeram a totalidade de instituiçóes brasileiras localizadas nas diversas regiôes do país.
\end{abstract}

PALAVRAS-CHAVE: Educação Especial. Deficiência visual. Revista Brasileira de Educação Especial.

\begin{abstract}
This study aimed to analyze the papers on visual impairment published in the Brazilian Journal of Special Education - RBEE, from its foundation, in 1992, to 2017, with the objective to highlight the participation of the area in publications in the Journal. The investigation identified 46 texts: three reviews, one comment and 42 papers, including essays, literature reviews and a research report. The comment and the reviews were excluded from the analysis. The reading and the analysis of the 42 papers adopted the following axes: annual distribution of the papers, authorship, themes, regions and institutions of origin, text genres and interfaces with other areas of knowledge. The results showed that the area of visual impairment is present in the academic production, with greater evidence over the last two decades. The themes of the papers encompassed different areas of knowledge, with an emphasis on the interface with the area of Health Sciences. The indicators regarding regions and institutions of origin revealed that, although the RBEE also publishes studies of international origin, the papers analyzed did not include the whole of the Brazilian institutions located in the several regions of the country.
\end{abstract}

KEYWORDS: Special Education. Visual impairment. Brazilian Journal of Special Education.

\section{INTRODUÇÃo}

No Brasil, a produção científica no campo da Educação Especial tem crescido muito nos últimos anos. Tal crescimento tem relação com a política de inclusão escolar em curso, deflagrada na década de 1990, e suas repercussóes no sistema educacional brasileiro marcado pelo emprego de uma pedagogia homogênea e de práticas e formas excludentes (Neres \& Corrêa, 2008, 2015; Lancillotti, 2006).

\footnotetext{
${ }^{1}$ http://dx.doi.org/10.1590/S1413-65382418000400011

${ }^{2}$ Pós-doutorado pela Universidade Federal de Mato Grosso do Sul - UFMS. Doutora em Educação pela Universidade de São Paulo - USP. Docente do Programa de Pós-Graduação Mestrado Profissional em Educação da Universidade Estadual de Mato Grosso do Sul - UEMS, Campo Grande - MS, Brasil. c.neres@uol.com.br.

${ }^{3}$ Doutora em Educação e Docente do Programa de Pós-Graduação em Educação pela Universidade Federal de Mato Grosso do Sul - UFMS, Corumbá - MS, e da Faculdade de Educação - FaEd, da Universidade Federal de Mato Grosso do Sul (UFMS), Campo Grande - MS, Brasil. nesdetemesquita@gmail.com
} 
Essa tendência crescente também se deve à ampliação da Pós-Graduação, espaço privilegiado na produção de pesquisa no campo da Educação Especial, conforme apontou a pesquisa de Sobrinho e Naujorks (2001, p. 10): "No Brasil a educação das pessoas com necessidades educacionais sugere uma concentração da produção do conhecimento nos Programas de Pós-Graduação stricto sensu [...]". Tais pesquisas e seus produtos divulgados por meio de relatórios, de dissertações, de teses e de artigos, têm evidenciado uma grande diversidade de objetos e de enfoques de investigação, além de múltiplas interfaces com diversas áreas do conhecimento. As tendências e os desenhos da pesquisa e da produção científica no campo da Educação Especial são demonstrados em estudos no campo, tais como: Manzini (2003), Bueno (2008), Omote (2003), Silva (2008), Nunes, Braun e Walter (2011), entre outros.

Essa ampliação do corpo de conhecimento tem sido relevante para o fortalecimento do campo e para o avanço de políticas e práticas direcionadas à educação de estudantes com deficiência, bem como em outras áreas de interface: saúde, assistência social e trabalho. Sobrinho e Naujorks (2001, p. 12) chamaram atenção para as lacunas na produção do conhecimento em Educação Especial. Os autores apontaram a necessidade de realização de "estudos de interface, em função do entrelaçamento de diferentes áreas do conhecimento" que envolvem o campo. Além disso, ressaltaram: a importância dos estudos mais amplos e de longo alcance, bem como o papel das universidades na formação de pesquisadores e de recursos humanos; e as investigaçóes em áreas específicas, tais como surdez ou deficiência auditiva, deficiência visual, estimulação precoce, altas habilidades e superdotação.

Diante do exposto, este artigo elegeu como foco de investigação a análise da produção científica, na forma de artigos, publicados na Revista Brasileira de Educação Especial (RBEE) na área da deficiência visual, no período de 1992 a 2017, com vistas a evidenciar como se configura a produção nesse recorte específico. Manzini (2003) pontua que:

A análise de produção em Educação Especial é um importante indicador para verificar as tendências de pesquisa no campo específico. Com esse indicador seria possível verificar se as políticas propostas para a área estão sendo atingidas ou se é necessário um redirecionamento de esforços para, realmente, atingir as necessidades prementes. (Manzini, 2003, p. 14).

A área da deficiência visual vem sendo objeto de estudo de muitos pesquisadores com o objetivo de contribuir para a avaliação e a proposição de políticas e práticas diretamente direcionadas às necessidades educacionais dessas pessoas. A definição do recorte do tema deste estudo justificou-se, inicialmente, pela constatação da ausência de estudos que abordem o mapeamento e a análise de publicaçóes na RBEE na área da deficiência visual, desde o seu lançamento em 1992. Aliado a isso, está o fato de as autoras deste estudo apresentar lastro de atividades profissionais no campo da Educação Especial na área da deficiência visual. Além disso, há, atualmente, o desenvolvimento de atividades docentes na produção de pesquisa e orientação de produçóes no âmbito da Pós-Graduação.

O presente estudo teve como objetivo analisar os artigos que abordam a deficiência visual publicados na RBEE nos seus 25 anos de existência ${ }^{4}$. O recorte proposto teve como fina-

4 Ver histórico da Revista Brasileira de Educação Especial em: Manzini, E. J. (2013). Avaliação de Periódicos Científicos: Revista Brasileira de Educação Especial. Revista Brasileira de Educação Especial, Marília, 19(1), 121-130. 
lidade evidenciar o registro dessa área nas produçóes veiculadas na RBEE, abrangendo, em sua análise da distribuição da produção, interfaces com outras áreas do conhecimento.

\section{MÉTODo}

Para analisar os artigos da RBEE que tratam da deficiência visual, utilizou-se do estudo bibliográfico com abordagem exploratório-descritiva. Esse tipo de estudo possibilita realizar um balanço de uma determinada área do conhecimento. Angelucci, Kalmus, Paparelli e Patto (2004) assinalam:

A importância de balanços periódicos do estado de coisas vigente numa área de pesquisa é múltipla. Eles podem detectar teoria e método dominantes; pôr em relevo aspectos do objeto de estudo que se esboçam nas entrelinhas das novas pesquisas; revelar em que medida a pesquisa recente relaciona-se com a anterior e vai tecendo uma trama que permita avançar na compreensão do objeto de estudo pela via do real acréscimo ao que já se conhece ou da superação de concepçôes anteriores. Só assim se podem avaliar as continuidades e descontinuidades teóricas e metodológicas e o quanto esta história se faz por repetiçấo ou ruptura — noutras palavras, o quanto ela redunda ou avança na produçáo de saber sobre o objeto de estudo [...]. (Angelucci, Kalmus, Paparelli, \& Patto, 2004, p. 53).

Ressalta-se que o periódico em tela assumiu, nesse transcurso, papel importante como veículo de divulgação e de socialização das pesquisas desenvolvidas no campo da Educação Especial. Nesse aspecto, ao longo dos anos, passou a ser a referência no que tange à qualidade da produção apresentada. Hoje, demonstra um alto padrão de qualidade editorial, conferido pelo Sistema WebQualis, da Coordenação de Aperfeiçoamento de Pessoal de Nível Superior (Capes).

A busca do material foi realizada em todos os números de publicaçóes da Revista no período de 1992 a 2017, sendo esse último o ano em que a RBEE completou os seus 25 anos, por meio da exploração dos sumários dos números publicados. O levantamento inicial foi feito no portal da Associação Brasileira de Pesquisadores em Educação Especial (ABPEE), que disponibiliza as publicaçóes da revista relativas aos anos de 1992 a 2005. Na sequência, a busca foi realizada no portal da Biblioteca Eletrônica SciELO, no qual se encontram disponibilizados os números da RBEE publicados do ano de 2006 a 2017. Foram selecionados aqueles estudos que, de alguma forma, abordam a deficiência visual, em um total de 46 publicaçóes encontradas: três resenhas, um comentário e 42 artigos nos gêneros textuais ensaio, revisão de literatura e relato de pesquisa. Excluíram-se, para o objeto de análise, o comentário e as resenhas.

A partir da leitura e análise dos 42 artigos, foram definidos os objetivos do estudo e os eixos de análise: distribuição anual dos artigos, autoria dos artigos, temas apresentados, regióes e instituiçóes de origem dos artigos, gêneros textuais e interfaces com outras áreas do conhecimento.

\section{RESUlTAdos E DiscuSSÃo}

Os resultados da análise desenvolvida expressam-se nos eixos de análise definidos, registrados pelos indicadores apresentados a seguir. 


\subsection{DistribuiÇáo ANUAL doS ARTigos PUbliCADOS (ANO/QUANTIDADE)}

Embora nos anos de 1993, 1997 e 1998 a RBEE não tenha sido publicada (Manzini, 2003), a presença de artigos na área da deficiência visual pode ser observada no periódico desde o início da publicação em 1992. Dos 42 artigos publicados ao longo de quase três décadas, ficou evidenciado que o maior número de publicaçóes ocorreu nas duas últimas, mais especificamente nos anos de 2007, 2011, 2013 e 2015 (Gráfico 1).

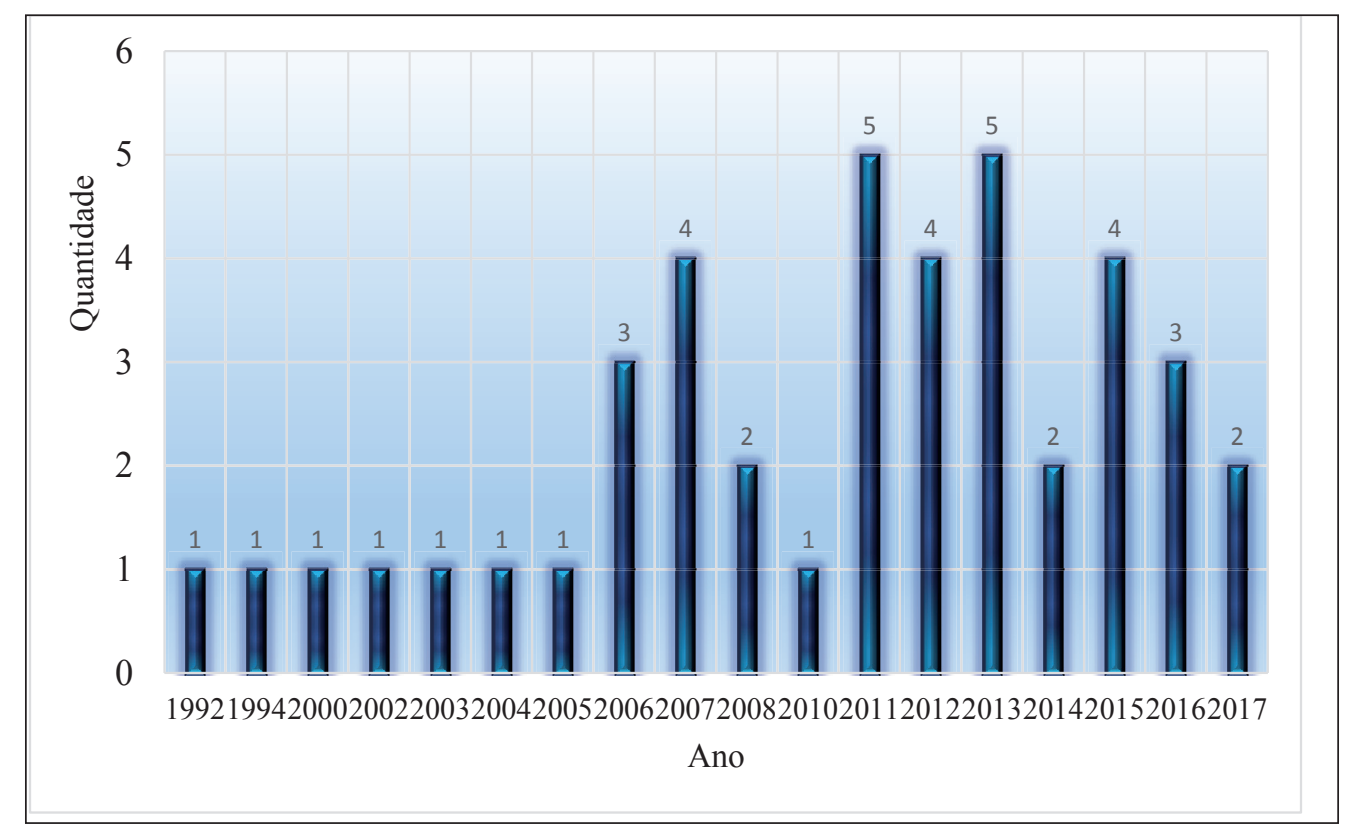

Gráfico 1. Número e ano dos artigos publicados (1992-2017) Fonte: Elaboração própria.

Esses dados vão ao encontro dos resultados do estudo realizado por Brito e Zeppone (2013) a partir de dados do Banco de Teses e Dissertaçôes da Capes e da Biblioteca Digital Brasileira de Teses e Dissertaçóes (BDTD - IBIC), que mapeou produçóes científicas sobre inclusão de pessoas com deficiência no Ensino Superior em nosso país, no período de 2000 a 2012. As autoras indicaram que a concentração do maior número de trabalhos nas áreas da deficiência se deu na investigação da deficiência visual, sendo $22 \%$ das publicaçóes oriundas de Programas de Pós-Graduação stricto sensu no Brasil.

Destaca-se que, nesse período, houve ampliação do movimento pelas políticas de Educação Inclusiva e de Educaçáo Especial no país. Em 2001, por meio das Diretrizes Nacionais para a Educação Especial na Educação Básica (Resolução CNE/CEB No 2, 2001); em 2008, com a publicação da Política Nacional de Educação Especial na Perspectiva da Educação Inclusiva (2008). Esses documentos impulsionaram várias políticas educacionais direcionadas à população com deficiência, implantadas pelo Ministério da Educação (MEC), 
posteriormente implementadas pelos estados e pelos municípios brasileiros, como foi o caso do Centro de Apoio Pedagógico para Atendimento às Pessoas com Deficiência Visual (CAP) ${ }^{5}$.

Infere-se que o número de produção científica na área da deficiência visual evidenciada nesse período possa estar relacionado às políticas educacionais direcionadas à essa população.

\subsection{AUTORIA DOS ARTIGOS PUBLICADOS}

A análise apreendida da autoria dos 42 artigos apontou a predominância de trabalhos elaborados por dois autores, $60 \%$ do total; $21 \%$ das produçóes realizadas por três autores; $12 \%$ individualmente; e, por fim, apenas três trabalhos foram elaborados por grupos de cinco autores.

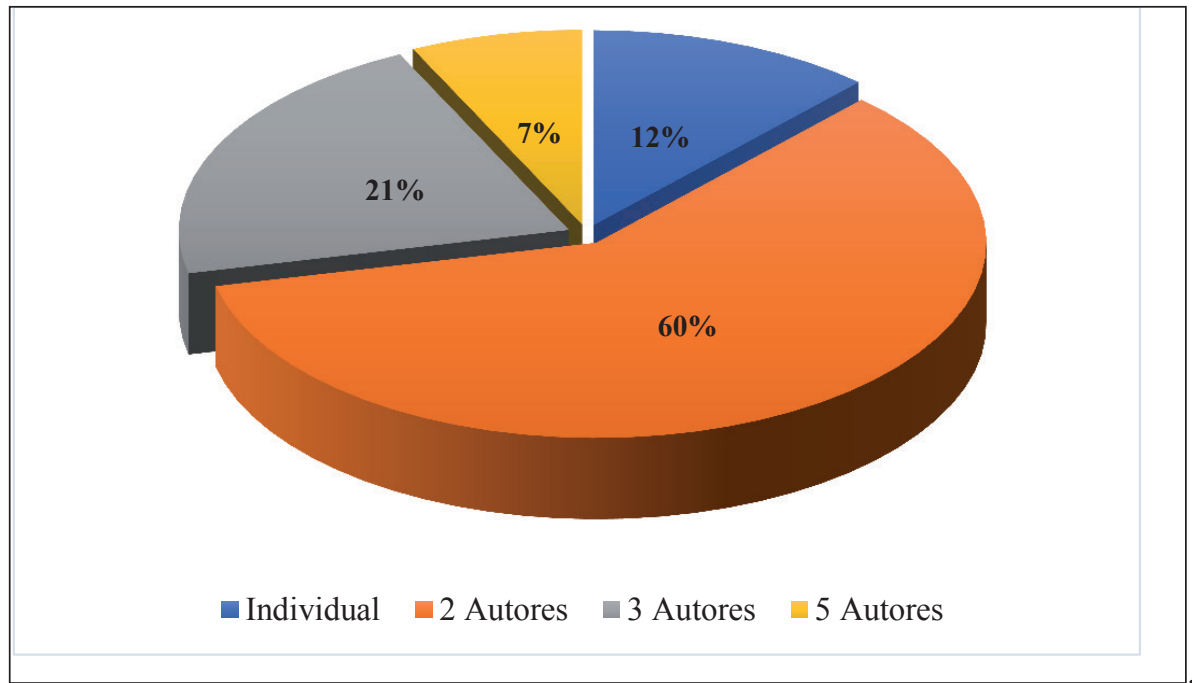

Gráfico 2. Autoria dos trabalhos

Fonte: Elaboração própria.

$\mathrm{Na}$ leitura dos artigos, foi possível observar que, em sua maioria, os trabalhos elaborados por dois autores estão associados à produção oriunda de trabalhos de Pós-Graduação, com a participação de orientadores, em coautoria. Os artigos produzidos por grupos de cinco autores são oriundos de áreas das Ciências da Saúde. A esse respeito, Montenegro e Alves (1997, p. 273) alertam que: "Cada vez que consultamos uma revista científica, especialmente aquelas voltadas à ciência médica, deparamos com trabalhos apresentados por numerosos autores. Aliás, este problema é internacional e já existem na literatura recente vários artigos abordando o assunto".

\footnotetext{
${ }^{5}$ Institucionalizado pelo MEC - Secretaria de Educação Especial (Seesp), em 1998, teve por meta viabilizar a implantação de pelo menos uma unidade do CAP em cada um dos estados brasileiros no período de 1998 a 2001. Constitui objetivo de o projeto garantir às pessoas cegas e às de baixa visão o acesso ao conteúdo programático desenvolvido na escola de ensino regular, bem como $\mathrm{o}$ acesso à literatura, à pesquisa e à cultura por meio da utilização de equipamentos da moderna tecnologia e da impressão do livro em Braille. Recuperado em 15 de março de 2018 de http://intervox.nce.ufrj.br/ -abedev/sintese_projeto_cap.html
} 
A presença de diversas áreas do conhecimento revela o aspecto interdisciplinar das publicaçóes da RBEE, assunto que será abordado no item 3.6 deste estudo.

\subsection{TeMAS RELACIONADOS À DEFICIÊNCIA VISUAL PRESENTES NOS ARTIGOS}

A maioria dos artigos (64\%) possibilitou o agrupamento dos temas, de acordo com o assunto abordado, assim distribuídos:

\begin{tabular}{|c|c|}
\hline Temas de estudo & $\begin{array}{l}\text { Número de } \\
\text { trabalhos }\end{array}$ \\
\hline Ações motoras/atividade psicomotora/locomoção/localização espacial & 5 \\
\hline Aprendizagem/concepçóes aprendizagem & 2 \\
\hline Brincadeiras/interação & 3 \\
\hline Desenvolvimento & 2 \\
\hline Educação sexual/sexualidade & 2 \\
\hline Ensino & 4 \\
\hline $\begin{array}{l}\text { Linguagem escrita/desenvolvimento da linguagem//linguística/linguagens acessíveis/comporta- } \\
\text { mentos pré-linguísticos e linguísticos/comunicação/interação }\end{array}$ & 7 \\
\hline Tecnologia/tecnologia assistiva & 2 \\
\hline $\begin{array}{l}\text { Outros temas (Avaliação educacional/ Concepções maternas e deficiência visual/ Consultoria } \\
\text { colaborativa para professores/ Cronobiologia e inclusão/ Deficiência visual e crianças indígenas/ } \\
\text { Díade mãe-criança/ Educaçáo em saúde bucal/ Facilitadores/barreiras e cegueira congênita/ } \\
\text { Identificação de habilidades/ Orientação a professores especializados/processos de escolarização/ } \\
\text { Tutoria de pares/ Substituição sensorial visuo-tátil e visuo-auditiva/adaptaçóes curriculares/ } \\
\text { experiência de visitantes) }\end{array}$ & 15 \\
\hline Total & 42 \\
\hline
\end{tabular}

Tabela 1. Temas de estudo dos artigos

Fonte: Elaboração própria.

Da mesma forma como sinalizado na autoria dos artigos, os temas também apontaram para diferentes áreas nas publicaçóes da RBEE. O maior número de artigos envolveu temas de linguagens, correspondendo a sete artigos (16\%) do total das publicaçóes; cinco artigos (12\%) desenvolveram temas relacionados a açóes/atividades motoras e questóes correlatas; quatro artigos $(9,5 \%)$ se concentraram no ensino. A multiplicidade de temas (outros temas) correspondeu a 36\% dos artigos publicados, reafirmando o desenho da revista em disseminar o conhecimento no campo da Educação Especial na interface com outras áreas.

\subsection{REgIÓES E INSTITUIÇÓES DE ORIGEM DOS ARTIGOS}

No que tange às regióes de origem dos artigos, verificou-se que apenas um artigo é de instituição internacional, Portugal, tendo a quase totalidade dos trabalhos de instituições brasileiras, localizadas em doze estados e no Distrito Federal. 
No Brasil, a região Sudeste predominou o número de publicações, representando 51\%. Tal volume de publicação pode ser compreendido pelo fato de a região Sudeste concentrar um maior número de Programas de Pós-Graduação, uma vez que as produçóes científicas se dão, em sua maioria, no interior desses Programas.

Cirani, Campanário e Silva (2015) apontam que, embora, nos últimos anos, há uma tendência a uma distribuição mais equânime dos Programas de stricto sensu no país, a região Sudeste ainda é a que tem o maior número: "Os dados comparativos entre as regióes brasileiras [...] apontam que, em 2011, de um total de 4.650 cursos de pós-graduação, 51\% estavam na região Sudeste, $20 \%$ no Sul, $18 \%$ no Nordeste, e somente 7,2\% no Centro-Oeste e $4 \%$ no Norte". Tal realidade influencia na produção científica, conforme sinalizam Cirani, Campanário e Silva (2015, p. 174): "Isso influencia diretamente a produção científica e tecnológica nacional e as perspectivas do crescimento regional, pois quanto mais cursos de pós-graduação, desde que implantados com qualidade, maior será a produção de conhecimento e seu efeito no desenvolvimento local”.

Os indicadores do Gráfico 3 ilustram, de forma detalhada, a distribuição das produçóes na área da deficiência visual.

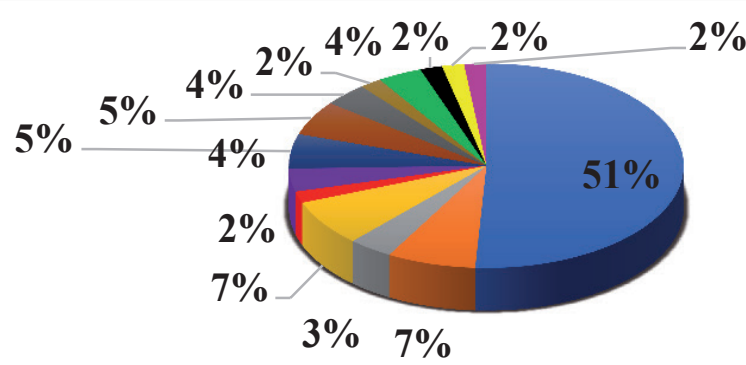

\begin{tabular}{|c|c|c|}
\hline SP/Sudeste & RJ/Sudeste & RS/Sul \\
\hline PR/Sul & ES/Sudeste & 口 DF/Centro-Oeste \\
\hline MG/Sudeste & MS/Centro-Oeste & PB/Nordeste \\
\hline PE/Nordeste & BA/Nordeste & - MA/Nordeste \\
\hline PA/Norte & - Portugal & \\
\hline
\end{tabular}

Gráfico 3. Localização de origem dos artigos publicados Fonte: Elaboração própria.

Já em relação à natureza administrativa das instituições, observou-se a predominância de instituiçóes públicas (93\%), revelando também o quadro geral da Pós-Graduação no Brasil. Cirani, Campanário e Silva (2015) mostram que, embora o número de mestrados e doutorados venha crescendo na esfera privada, o setor público ainda é o que apresenta maior número de cursos nesse nível. Os autores afirmam que: "A ampliação dos cursos públicos se deu de forma significativa sob a ótica do número total de cursos. Enquanto entre 1998 e 2011 
a taxa de expansão do setor público correspondeu a de 105\%, para uma base já grande, de cerca de 10 vezes o número do setor privado" (Cirani, Campanário, \& Silva, 2015, p. 172).

Os dados do Gráfico 4 registram o quadro geral da natureza administrativa das instituições de origem dos estudos.

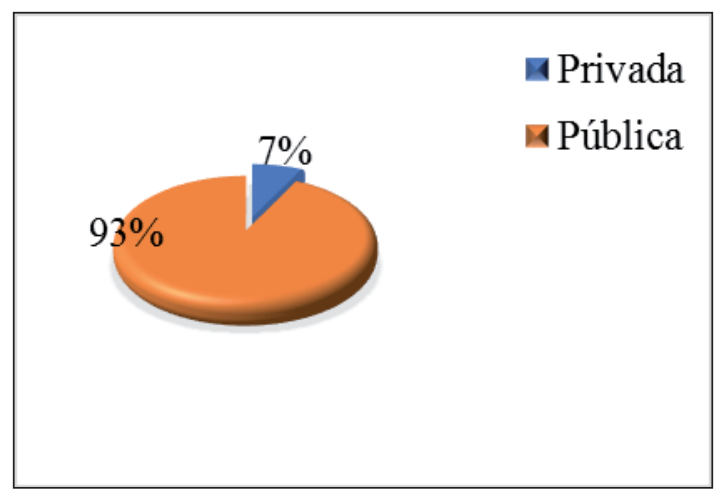

Gráfico 4. Natureza administrativa das instituiçóes de origem dos estudos Fonte: Elaboração própria.

No que diz respeito às instituições de origem dos artigos, os dados evidenciam que a produção é realizada por muitas instituições de Ensino Superior (IES). Nos registros feitos nos artigos, aparecem 27 IES, como podemos observar no Gráfico 5. 


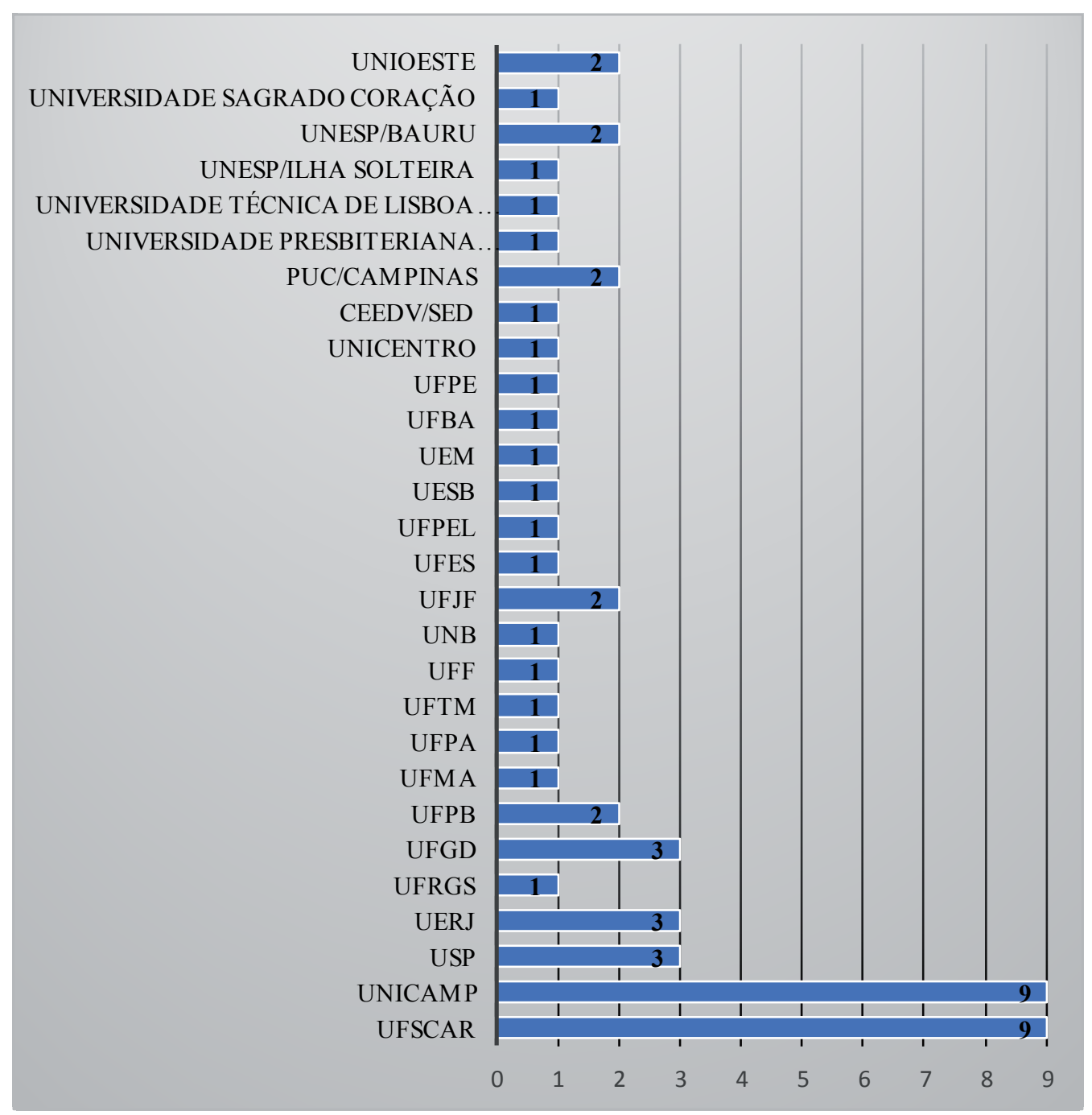

Gráfico 5. Instituiçôes de origem dos estudos Fonte: Elaboração própria.

As universidades que aglutinaram maior número de artigos foram a Universidade Federal de São Carlos (UFSCar) e a Universidade Estadual de Campinas (Unicamp), ambas localizadas na região Sudeste onde se concentra o maior número de Programas de Pós-Graduação em educação no país.

\subsection{GÊNERO TEXTUAL DOS ARTIGOS}

Em relação aos gêneros textuais, a classificação foi feita segundo os tipos indicados no sumário de cada revista e em cada artigo: ensaio, revisáo de literatura e relato de pesquisa. Foram analisados 42 artigos relacionados à deficiência visual. Desses, $88 \%$ são relatos de pes- 
quisa; $10 \%$ são revisões de literatura e apenas $2 \%$ se enquadram em ensaio. Tal frequência pode ser observada no Gráfico 6:

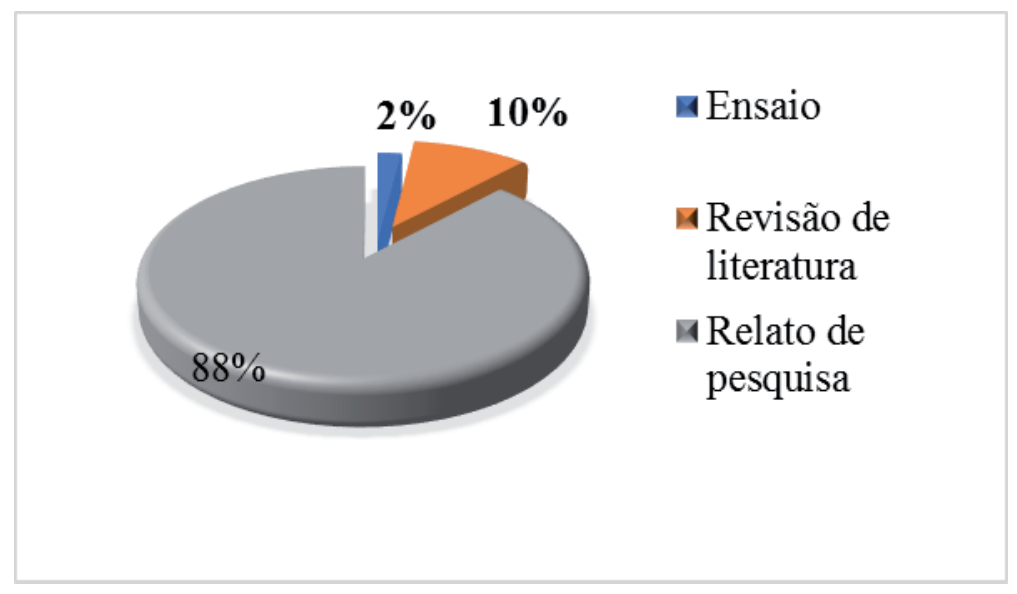

Gráfico 6. Gênero textual dos artigos

Fonte: Elaboração própria.

O predomínio do relato de pesquisa nas publicaçóes pode ser explicado pela correspondência com as pesquisas realizadas em Programas de Pós-Graduação, uma vez que são o lócus de desenvolvimento das produçóes científicas na área da educação. Essa preponderância pode também ser consequência do próprio perfil da área da educação e seus grupos de pesquisa, como também da RBEE que guarda referência na divulgação dos estudos em periódicos. Manzini (2013, p. 121), ao tecer o histórico da RBEE, pontua que ela é fruto da preocupação de alguns pesquisadores em "divulgar e disseminar conhecimento sobre Educação Especial".

Azevedo, Giroto e Santana (2015) lembram que a pouca prevalência dos gêneros ensaio e revisão de literatura pode ser explicada pela quantidade de trabalhos enviados para a revista, como também pode ter relação com as normas para publicação definidas pelo periódico. As autoras ressaltam ainda que o ensaio não é um gênero comum nas produçóes da academia.

\section{6 ÁREAS DE CONHECIMENTO EVIDENCIADAS NOS ARTIGOS}

No que se refere às áreas de conhecimento ${ }^{6}$ contempladas nas produçóes dos artigos, foi observada a indicação das instituiçóes, das faculdades, dos departamentos, dos cursos, dos programas de Pós-Graduação e demais órgãos de origem dos autores.

$\mathrm{Na}$ análise das áreas de conhecimento, nos 42 artigos analisados, ficou evidenciada a interface da Educação Especial com mais de dez áreas de conhecimento. Tal incidência revela o caráter interdisciplinar das publicaçóes, sobretudo no campo da Educação Especial, mostrando identidade da RBEE e seu caráter multidisciplinar, já apontada por Manzini, Correa e Silva (2009).

\footnotetext{
${ }^{6}$ Tomou-se como referência para a classificação das áreas, a Tabela de conhecimento do CNPq. Recuperado em 15 de Março de 2018 de http://www.cnpq.br/documents/10157/186158/TabeladeAreasdoConhecimento.pdf.
} 


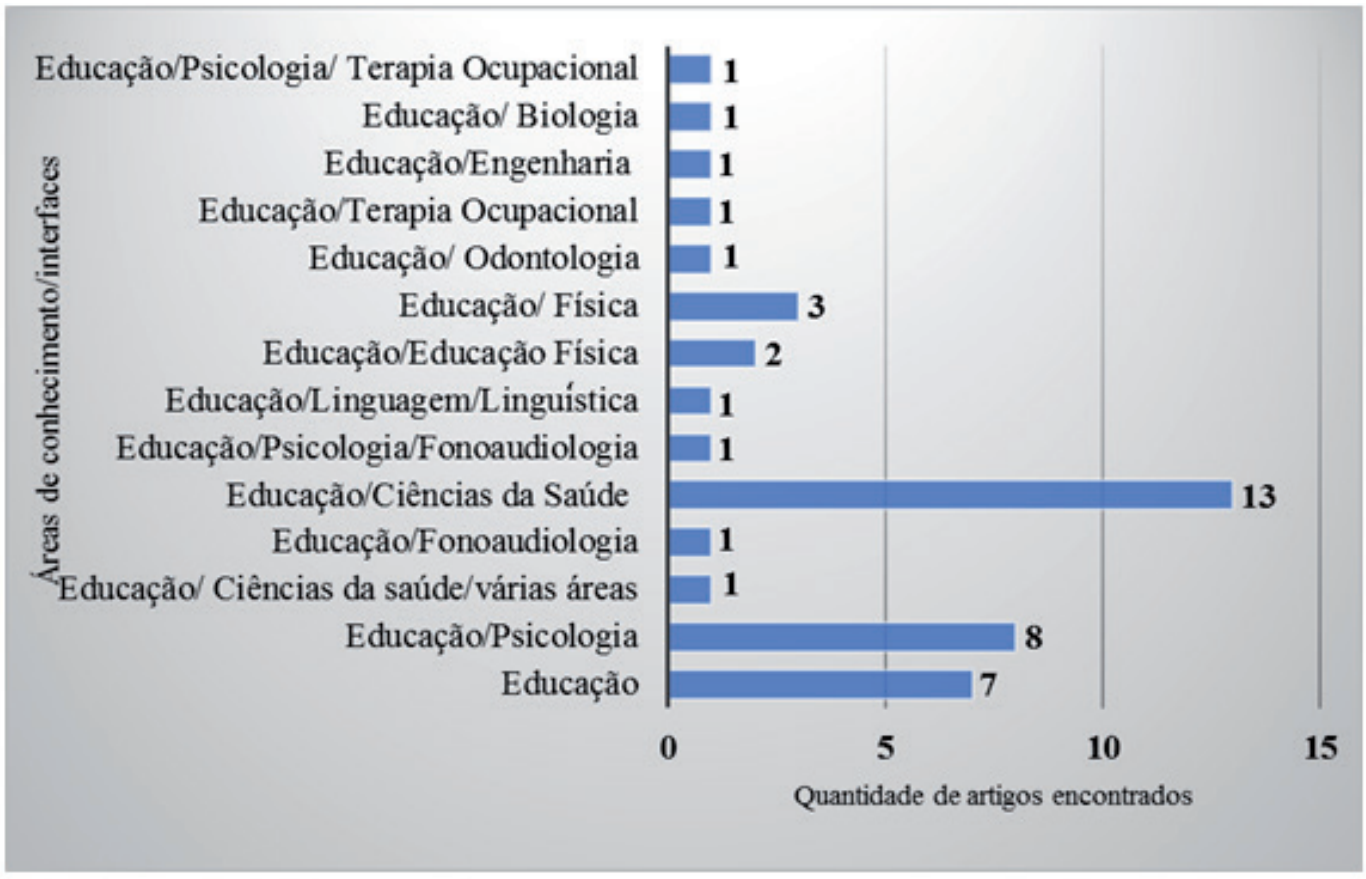

Gráfico 7. Áreas de conhecimento Fonte: Elaboração própria.

Da mesma forma, essa característica pode ser constatada no próprio formato que assume o campo da Educação Especial e suas relaçôes com a saúde, assistência social, justiça, trabalho e a necessidade do desenvolvimento de açóes intersetoriais para melhor desenvolvimento e aprendizagem das pessoas com deficiência. Essa natureza tem sido contemplada na política e na legislação educacional vigente como apoio ao atendimento educacional especializado (AEE).

Ressalta-se o foco dos artigos nas Ciências da Saúde, compreendendo: medicina, oftalmologia e suas derivações, com treze publicaçōes. Outra área que a Educação Especial mostrou interface interessante é com a psicologia, com oito trabalhos apresentados.

No tocante à saúde, observou-se uma tendência recente na área de estudos no âmbito da educaçáo, seja na formaçáo dos profissionais como também na defesa da prevenção, da proteçâo e da promoçẫo da saúde. Há em curso uma política de saúde que está calcada nessa orientação desde a criação do Sistema Único de Saúde (SUS), focada nos princípios de universalidade e integralidade, abordagem multidisciplinar. Feuerwerker (2007) destaca que:

Ao longo dos últimos 15 anos de implementação do SUS, foram sendo acumuladas experiências e reflexões a respeito dos limites e possibilidades de diferentes iniciativas de mudança na formação dos profissionais de saúde. Então, em comum com o movimento da reforma sanitária brasileira, o movimento de mudanças na formação tem o compromisso ético-político com a saúde da população brasileira e com os princípios do SUS. (Feuerwerker, 2007, p. 1). 
Estudos que enfocam educação e saúde são importantes como forma de difundir conhecimentos, experiências que ajudem no processo de escolarização e inclusão escolar de estudantes com deficiência visual. Bernal (2008), ao analisar a interface entre saúde e educação no contexto da inclusão escolar, afirmou que:

[...] a articulação entre saúde e educação como direito dos alunos com deficiência, expressa na ação da saúde desmistificando a patologia, esclarecendo os processos individuais, ampliando as formas de interação entre a equipe escolar, os colegas e o aluno com deficiência, contribuindo no planejamento e na implementação de recursos e alternativas que possam favorecer o professor e a escola no atendimento das necessidades educativas especiais de cada aluno que as apresente. (Bernal, 2008, p. 184).

A pesquisadora em questão problematizou a interseção da saúde e da educação apontando para a necessidade de mais aproximação e diálogo entre as áreas para que se façam valer os princípios da integralidade, da universalidade e o caráter multidisciplinar que exige a ação educativa. Chama, assim, atenção para a urgência da revisão dessa relação. Nesse sentido, a ampliação de estudos e de pesquisas que investiguem esse campo de interseção é fundamental.

\section{Consideraçótes finais}

Este estudo, ao analisar os 42 artigos na área da deficiência visual publicados na RBEE no percurso dos seus 25 anos de existência (1992-2017), possibilitou desvelar o quanto a área da deficiência visual tem sido eleita como objeto de investigação pela produçáo acadêmica desde o início da veiculação da RBEE, o que indica a importância dos estudos nessa área para a ampliação do conhecimento no campo da Educação Especial.

Os eixos definidos para análise do objeto de estudo proporcionaram conhecer a distribuição anual dos artigos, a autoria dos artigos, os temas apresentados, as regiôes e as instituiçóes de origem dos artigos, os gêneros textuais e interfaces com outras áreas do conhecimento.

A distribuição anual dos artigos, ao sinalizar a frequência de publicação de estudos na área da deficiência visual, indicou que esta ocupa constante espaço de investigação na produção acadêmica, com mais evidência nas duas últimas décadas, condição necessária para a ampliação do conhecimento e avanço de políticas e práticas direcionadas à educação das pessoas com deficiência visual.

A autoria dos artigos com predomínio de relato de pesquisa e de trabalhos elaborados com a participação de orientadores, em coautoria, demarcou o papel da Pós-Graduação no universo de publicação acadêmica, lócus de desenvolvimento das produçóes científicas na área da educação.

Os temas dos artigos, ao se constituírem por diferentes áreas do conhecimento, não apenas reafirmaram o papel da RBEE de disseminar conhecimento no campo da Educação Especial na interface com outras áreas do conhecimento, bem como assinalaram o envolvimento de outras áreas, além da educação, na produção científica nesse campo, com destaque para a interface com a área da saúde. Tal configuração demarca o caráter multidisciplinar e intersetorial da Educação Especial, condição salutar para o desenvolvimento e a aprendizagem, principalmente das pessoas com deficiência. 
Os indicadores de regióes e instituiçôes de origem dos artigos na área da deficiência visual revelaram que, embora a RBEE contemple estudo oriundo de instituição internacional e estudos oriundos de doze estados e do Distrito Federal, a concentração da publicação brasileira dá-se na Região Sudeste, na qual se encontra o maior número de Programas de Pós-Graduação.

Nesses últimos 25 anos, o acervo de publicaçóes disponibilizado pela Revista Brasileira de Educação Especial, sobretudo aquelas resultantes de pesquisas, denota o espaço de destaque que a revista representa como promotora de intercâmbio técnico-científico no campo da Educação Especial e áreas afins em nosso país.

\section{REFERENCIAS}

Angelucci, C. B., Kalmus, J., Paparelli, R., \& Patto, M. H. S. (2004). O estado da arte da pesquisa sobre o fracasso escolar (1991-2002): Um estudo introdutório. Educação e Pesquisa, 30(1), 51-72.

Azevedo, C. B., Giroto, C. R. M., \& Santana A. P. O. (2015). Produção científica na área da surdez: Análise dos artigos publicados na Revista Brasileira de Educação Especial no período de 1992 a 2013. Revista Brasileira de Educaçâo Especial, 21(4), 459-476.

Bernal, C. M. F. (2008). Atendendo às diferenças: A interface entre saúdeleducação no contexto da educação comum inclusiva (Tese de Doutorado). Universidade Metodista de Piracicaba, Piracicaba, São Paulo, Brasil.

Brasil. (2001). Resolução CNE/CEB no 2, de 11 de setembro de 2001. Institui Diretrizes Nacionais para a Educação Especial na Educação Básica. Recuperado em 19 de abril de 2003 de http://www.inep. gov.br

Brasil. (2008). Política Nacional de Educação Especial na Perspectiva da Educação Inclusiva Recuperado em 20 de maio de 2008 de http://portal.mec.gov.br/seesp/arquivos/pdf/politica.pdf

Brito, J., \& Zeppone, R. M. O. (2013). Mapeamento de Teses e Dissertaçóes sobre a inclusão de pessoas com deficiência no Ensino Superior no Brasil (pp. 96-111). Anais do Encontro da Associação Brasileira de Pesquisadores em Educação Especial, Londrina, PR, Brasil, 8. Recuperado em 4 de julho de 2018 de http://www.uel.br/eventos/congressomultidisciplinar/pages/arquivos/anais/2013/AT01-2013/ AT01-010.pdf

Bueno, J. G. S. (2008). A produção acadêmica sobre inclusão escolar e educação inclusiva. In E. G. Mendes, M. A. Almeida, \& M. C. P. I. Hayashi (Orgs.), Temas em educação especial: Conhecimentos para fundamentar a prática (pp. 31-47). Araraquara: Junqueira \& Marin; Brasília, DF: CAPESPROESP.

Cirani C. B. S., Campanario, M. A., \& Silva, H. H. M. (2015). A evolução do ensino da pós-graduação senso estrito no Brasil: Análise exploratória e proposições para pesquisa. Revista Avaliação, 20(1), 163-187.

Feuerwerke, L. C. M. (2007). Educação na saúde - Educação dos profissionais de saúde - Um campo de saber e de práticas sociais em construção. Revista Brasileira de Educação Médica, 31(1), 3-4.

Lancillotti, S. S. P. (2006). A organização do trabalho didático como categoria de análise para a educação especial. In C. C. Neres, \& S. S. P. Lancillotti (Orgs.), Educação especial em foco: Questóes contemporâneas. Campo Grande, MS: UNIDERP. 
Manzini, E. J. (2003). Análise de artigos da Revista Brasileira de Educação Especial (1992-2002). Revista Brasileira de Educação Especial, 9(1), 13-24.

Manzini, E. J. (2013). Avaliação de periódicos científicos: Revista Brasileira de Educação Especial. Revista Brasileira de Educação Especial, 19(1), 121-130.

Manzini, E. J., Correa, P. M., \& Silva, M. O. (2009). Disseminação de conhecimento em educação especial no Brasil: As contribuições da ABPEE. Revista Brasileira de Educação Especial, 15, 181-196.

Montenegro, M. R., \& Alves, V. A. F. Critérios de autoria e co-autoria em trabalhos científicos. Acta bol, 11(2), 273-276.

Neres, C. C., \& Corrêa, N. M. (2008). O trabalho como categoria de análise na educação do deficiente visual. Caderno Cedes, Campinas, 28(75), 149-170.

Neres, C. C., \& Corrêa, N. M. (2015). Tecnologias assistivas no processo de escolarização de alunos com deficiência sensorial. Educação e Fronteiras On-Line, 5(13), 163-174.

Nunes, L. R. O. P., Braun, P., \& Walter, C. C. F. (2011). Procedimentos e recursos de ensino para o aluno com deficiência: O que tem sido disseminado nos trabalhos do GT 15 da ANPED sobre estes temas? Revista Brasileira de Educação Especial, 17(Ed. Espec.), 23-40.

Omote, S. (2003). Algumas tendências (ou modismos?) recentes em Educação Especial e a Revista Brasileira de Educação Especial. Revista Brasileira de Educação Especial, 9(1), 25-38.

Silva, R. H. R. (2008). Análise epistemológica das dissertaçóes e teses em educação especial. Anais da Reunião Anual da Associação Nacional de Pesquisadores em Educação, Caxambu, MG, Brasil, 31. Recuperado em 4 de julho de 2018 de http://www.anped.org.br/sites/default/files/gt15-4610-int. pdf.

Sobrinho, F. P. N., \& Naujorks, M. I. (2001). Introdução - Pesquisas em Educação Especial - O desafio da qualificação. In F. P. N. Sobrinho, \& M. I. Naujorks (Orgs.), Pesquisas em Educação Especial-O desafio da qualificação. Bauru-SP: EDUSC.

Recebido em: 20/03/2018

Reformulado em: 24/04/2018

Aceito em: 24/04/2018 